\title{
Association of life course socioeconomic status and adult height with cognitive functioning of older adults in India and China
}

\author{
Y. Selvamani ${ }^{1^{*}}$ (1) and P. Arokiasamy ${ }^{2}$
}

\begin{abstract}
Background: Cognitive functioning is an important measure of intrinsic capacity. In this study, we examine the association of life course socioeconomic status (SES) and height with cognitive functioning among older adults (50+) in India and China. The age pattern of cognitive functioning with measures of life course socioeconomic status has also been examined.

Methods: Cross-sectional comparative analysis was conducted using the WHO's Study on global AGEing and adult health (SAGE) data for India and China. Multilevel mixed-effect linear regression analysis was used to examine the association of life course socioeconomic status and adult height with cognitive functioning.

Results: In both India and China, parental education as a measure of childhood socioeconomic status was positively associated with cognitive functioning. The association between adult socioeconomic status and cognitive functioning was positive and significant. Height was significantly and positively associated with improved cognitive functioning of older adults in India and China. Furthermore, the age-related decline in cognitive functioning score was higher among older adults whose parents had no schooling, particularly in China. The cognitive functioning score with age was much lower among less-educated older adults than those with higher levels of education in China. Wealthier older adults in India had higher cognitive functioning in middle ages, however, wealth differences narrowed with age.
\end{abstract}

Conclusions: The results of this study suggest a significant association of lifetime socioeconomic status and cumulative net nutrition on later-life cognitive functioning in middle-income settings.

Keywords: Childhood socioeconomic status, Stature, Cognition, Intrinsic capacity, WHO-SAGE, Ageing

\section{Background}

Rapid demographic changes such as the reduction in fertility and improvements in health have resulted in the rise of life expectancy both in India and China, the two most populated nations in the world with more than a third of the global population. In addition to the one

\footnotetext{
*Correspondence: selvinsw@gmail.com

'International Institute for Population Sciences (IIPS), Govandi Station Road, Mumbai 400088, India

Full list of author information is available at the end of the article
}

child policy, the rise in life expectancy was faster in China than in India and as a result, the share of the elderly population is rising rapidly [1]. By 2050 , the projected elderly population $(60+)$ to reach $36.5 \%$ in China and $19.4 \%$ in India, respectively [2].

The age-associated changes in mental health conditions such as cognitive impairment, depression and dementia are significant contributors to the global disease burden [3-5]. Individuals who maintain better cognitive functioning in early years and old age have better

(C) The Author(s). 2021 Open Access This article is licensed under a Creative Commons Attribution 4.0 International License, which permits use, sharing, adaptation, distribution and reproduction in any medium or format, as long as you give appropriate credit to the original author(s) and the source, provide a link to the Creative Commons licence, and indicate if changes were made. The images or other third party material in this article are included in the article's Creative Commons licence, unless indicated otherwise in a credit line to the material. If material is not included in the article's Creative Commons licence and your intended use is not permitted by statutory regulation or exceeds the permitted use, you will need to obtain permission directly from the copyright holder. To view a copy of this licence, visit http://creativecommons.org/licenses/by/4.0/ The Creative Commons Public Domain Dedication waiver (http://creativecommons.org/publicdomain/zero/1.0/) applies to the data made available in this article, unless otherwise stated in a credit line to the data. 
outcomes such as improved quality of life, lower risk of disabilities and all-cause mortality [6-10]. While cognitive functioning is an important measure of intrinsic capacity [11], evidence suggests that the secular improvement in the levels of cognitive functioning [12] and socioeconomic position across the globe [13, 14]. Individual improvement in cognition is mainly driven by conditions during childhood and adult life, such as improvement in childhood health, nutrition, and better socioeconomic conditions and structural factors [15-19].

A growing body of literature suggests a significant association between childhood socioeconomic status and health conditions with cognitive functioning in later life. Childhood socioeconomic status plays an important role in determining the higher educational attainment, immunisation, health, and nutrition which have a significant impact in later life [20-23]. Studies mainly from high-income countries showed strong association of adverse childhood circumstances such as poor socioeconomic status, and childhood poverty/deprivation with poor cognitive functioning, cognitive impairment, and dementia [24-31]. However, very few studies have examined the association between life course socioeconomic status and cognitive functioning in low and middleincome countries [32].

Furthermore, literature shows the linkages of height with health, physical, and cognitive functioning. Adult height is a summary measure of health and net nutrition in early childhood [33-35]. The height of the individual makes significant difference from childhood on various outcomes of health and wellbeing [36]. Taller children perform well in school, sports, and cognitive functioning tests, and secure higher positions. On average taller people have a more economic advantage than short people; taller people earn more than their shorter counterparts [37, 38]. Also, taller older adults have higher cognitive functioning than their shorter counterparts $[39,40]$ and are at lower risk of developing dementia [41-43]. It is also notable that the income-height relationship mediates through higher cognitive functioning [37]. Height is also associated with better health, happiness, and overall quality of life [44-46].

Studies reflecting association between the life course socioeconomic status and height and cognitive functioning are limited in middle-income countries. In this paper, we examine the association of childhood socioeconomic status (parental education and employment), adult height, and adult socioeconomic status (own education and wealth quintile) with cognitive functioning among older adults in two middle-income countries, namely, India and China using WHO-SAGE Wave 1 data. We also examine the age pattern of cognitive functioning score across the life course socioeconomic conditions.

\section{Methods \\ Data and sample WHO study on global AGEing and adult health (SAGE)}

In this paper, data from the WHO's SAGE survey, a nationally representative household health survey conducted in six low and middle-income countries: China, Ghana, India, Mexico, the Russian Federation, and South Africa during 2007-10 is used. SAGE data was collected by the World Health Organisation (WHO) with support from national and international organisations. The main aim of SAGE survey was to fulfil the data gaps and understand the health and well-being of the growing ageing population in the six low and middle-income countries. SAGE measures are comparable with other studies from high-income countries such as the Health and Retirement Study (HRS), and the Survey of Health, Ageing and Retirement in Europe (SHARE). A multistage, stratified clustered sample design was used homogeneously in all the countries to collect the data from the older adults. SAGE included a sample of 34,124 older adults aged 50 and above and a comparative sample of 8307 adults aged 18-49.SAGE collected data on self-reported as well as biomarkers on different domains of health, wellbeing, and anthropometric indicators. Height was measured by trained health investigators. Besides, SAGE also collected data on parental characteristics such as parental education and employment. This analysis was conducted on the cross-sectional sample of 19,666 older adults aged 50 years and above for India $(n=6560)$ and China $(n=13,106)$ based on WHOSAGE Wave 1 data conducted during 2007-10. SAGE is a longitudinal survey, however, at the time of the data analysis, only Wave 1 data was available. More detailed information on sampling, methodology and data are provided in Kowal et al. (2012) [47].

The SAGE study was approved by the Ethics Review Committee (RPC146), World Health Organization, Geneva, Switzerland and the Institutional Review Board, International Institute of Population Sciences, Mumbai, India and the ethics review committee of the Chinese Canter for Disease Control and Prevention (China CDC) (Approval notice 200,601).

\section{Outcome variable}

\section{Cognitive functioning}

SAGE survey collected information on cognition measures such as immediate and delayed verbal recall, verbal fluency, and forward and backward digit span. In this analysis, we generated a standardised cognitive function index combining the variables covering three domains of cognition using principal components analysis and the final score of this index ranged from 0 to 100; higher scores represent higher cognitive functioning [48]. A 
detailed description of the process of cognitive functioning variable construction is presented in the supplementary file.

\section{Predictor variables Childhood socio-economic status (SES)}

SAGE collected data on parental education and work status/employer for mother and father. The parental education responses were captured in seven categories from no formal education to post-graduation. For the analysis, we categorized parental education into four categories: no formal education, less than primary, completed primary or secondary, and completed higher secondary (HS) or above. Parental employment was recoded into four categories; not employed, selfemployed, employed in the informal sector, employed in the private sector/public sector.

\section{Height}

In the SAGE survey, height was measured in centimetres using a stadiometer by trained health investigators. In the analysis, sex and country-specific height quintiles were generated to examine the association between height and cognitive functioning in India and China. The height quintile distribution of the study population for India and China is presented in the supplementary file.

\section{Measures of adult SES}

In this study, educational attainment, wealth quintile and work status have been included as measures of adult socioeconomic status. Educational attainment was categorized as 'no formal education', 'less than primary', 'completed primary or secondary', and 'completed higher secondary (HS) or above'. Wealth quintile variable was generated from measures of household amenities and ownership of durable goods and categorised as 'poorest', 'poorer', 'middle', 'richer', and 'richest'. A list of household wealth variables was used to calculate the wealth quintile which is provided in supplementary Table 1. The work status of the study participants was categorised as 'not employed', 'self-employed', 'informal sector', and 'private sector/public sector'.

\section{Life course SES}

We generated a life course SES variable to understand the social mobility and cognitive functioning among the older adults in India and China [49]. Education-based life course SES was generated by combining parental and own education and defined as: 1. 'Stable low' when parental and respondents' education was less than primary; 2. 'Declining' when parental education is greater than primary and respondents' education was less than primary; 3. 'Increasing 'when parental education was less than primary and respondents' education was greater than primary; 4. 'Stable high 'when parental education was greater than primary and respondent's education was greater than primary. Employment-based life course SES was generated by combining parental and own employment status and defined as: 1. 'Stable low' when parent and the respondent were both not employed; 2 . 'Declining' when a parent was employed and the respondent was not employed; 3. 'Increasing' when a parent was not employed and respondent was employed; 4. 'Stable high' when parent and respondent were both employed. The distribution of sample according to life course SES variables is presented in supplementary file.

\section{Demographic and health characteristics}

We included selected demographic and health variables as covariates which include age (years), place of residence (urban/rural), marital status (currently married/ otherwise), body mass index (underweight $(<18.5 \mathrm{~kg} /$ $\mathrm{m}^{2}$ ), normal $\left(18.5-24.9 \mathrm{~kg} / \mathrm{m}^{2}\right)$, overweight (25.0-29.9 $\left.\mathrm{kg} / \mathrm{m}^{2}\right)$, and obesity $\left.\left(30.0+\mathrm{kg} / \mathrm{m}^{2}\right)\right)$, poor self-rated health (SRH) (no/yes). Self-reported depression (no/yes).

\section{Activities of daily living $(1+A D L)$ limitations}

Data on the questions measuring difficulties in doing activities in the last 30 days have been used to generate" $1+$ ADL limitations' variable. These questions captured difficulties in 'sitting for long periods', 'walking 100 meters', 'standing up from sitting down', 'standing for long periods', 'climbing one flight of stairs without resting', 'stooping/kneeling/crouching', 'picking up things with fingers', 'extending arms above shoulders', 'concentrating for $10 \mathrm{~min}$ ', 'walking a long distance $(1 \mathrm{~km})$ ', 'bathing, getting dressed', 'carrying things', 'moving around inside home', 'getting up from lying down', and 'getting to and using the toilet'. We recoded severe and extreme difficulties to represent difficulties in activities of daily living. Further, we summed up these measures into one variable and coded " 0 " as no difficulty" else (one or more) into " 1 " to represent $1+$ ADL limitations.

\section{Sleep problems}

In the SAGE survey, the prevalence of sleep problems was determined with the following question 'Overall in the last 30 days, how much of a problem did you have with sleeping, such as falling asleep, waking up frequently during the night or waking up too early in the morning?' response categories were none, mild, moderate, severe, extreme/cannot do. Those who reported 'severe' and 'extreme/cannot do' were considered as having sleeping problems.

\section{Edentulism (loss of all natural teeth)}

The prevalence of complete tooth loss was assessed with the following question. 'Have you lost all of your natural 
teeth?' Those who said yes were coded as 1 "edentulous" else into 0 "dentate'.

\section{Health Behaviours Physically inactive}

Those who reported physical activity less than $300 \mathrm{~min}$ in a week are considered as physically inactive. Tobacco use was categorised as yes or no. Alcohol consumption was categorised as yes if the respondent consumed 1-4 days/week or more in the last 12 months' or no.

\section{Statistical analysis}

Bivariate analysis was used to understand the sample distribution by background characteristics. Further, we assessed the association of life course socioeconomic status and height (quintile) and cognitive functioning using multilevel mixed-effect regression models. Three-level random intercept regression models were used which included province at the first level, Primary Sampling Unit (PSU) at second, and individual at the third level. Furthermore, to understand the age patterns of cognitive functioning trajectories by life course socioeconomic status, the interaction of life course socioeconomic status measures such as parental education and adult socioeconomic status (schooling and wealth quintile) with age were used. All analyses were carried out in STATA 15.0.

\section{Results}

\section{Study participants}

Descriptive statistics of the study participants are provided in Table 1 . The mean age of study participants was 61.5 years in India and 61.6 years in China. Older adults in China were slightly taller than their counterparts in India. The distribution of the sample by place of residence showed that more than half of the sample were from rural areas in India (71\%) and China (53\%). A large proportion of study participants in China were currently married $(85.0 \%)$ as compared to $77 \%$ in India. In India, more than half of older adults (51\%) had no formal education. About $27 \%$ of older adults in India have never worked. In India and China, around $90 \%$ of the participant's mother had no schooling. In India and China, more than $65 \%$ of the study participant's father had no schooling. In India, about $65 \%$ of the study participant's mother never worked, compared to $38.7 \%$ in China. A higher percentage of older adults in India reported sleep problems (14.5\%), compared to $2.7 \%$ in China. Similarly, the prevalence rate of loss of all natural teeth (edentulism) was higher in India (15\%) and a large proportion of the study participants in India were underweight (38\%). The prevalence of poor self-rated health among study participants was 22.4 and $21.2 \%$ in India and China, respectively. More than half of the study participants in India reported $1+\mathrm{ADL}$ limitations. The prevalence of tobacco use was higher in India (47\%) and the prevalence of physical inactivity was higher in China.

The overall age-adjusted mean cognitive functioning score was higher among older adults in China (51.3) than India counterparts (37.7). Older women in India and China had lower cognitive functioning score than men (Fig. 1). The correlation between the main outcome variable (cognitive functioning) and measures of life course socioeconomic status, height, demographic and health measures is presented in supplementary file.

\section{Results from multivariate analysis}

Results from multilevel multivariate regression models showed that parental education was significantly and positively associated with late-life cognitive functioning in India and China (Table 2). The association between father's education and cognitive functioning was strong and positive. Older adults in India and China whose fathers completed higher secondary (HS) or above had higher cognitive functioning score $(\beta=2.53, \mathrm{CI}$ : 1.36 , $3.69, p<.001)$ and $(\beta=3.50, \mathrm{CI}: 2.43,4.57, \mathrm{p}<.001)$ than of older adults whose fathers had no schooling, respectively. Similarly, older adults in India and China whose mothers completed high school or above had 3.07 (CI: $0.59,5.56, p<.005$ ) and 2.17 (CI: 0.54, 3.80, $p<.001$ ) higher cognitive functioning score than of older adults whose mothers had no schooling.

In India, father's employment was positively associated with cognitive functioning. Further, height is strongly and positively associated with the cognitive functioning score. Older adults in the highest height quintile category in India $(\beta=1.81, \mathrm{CI}: 1.15,2.47, \mathrm{p}<.001)$ and China $(\beta=2.23$, CI: $1.60,2.86, \mathrm{p}<.001)$ had a better cognitive functioning score, respectively. Educational attainment of the study participants and wealth quintile were found as strong predictors of cognitive functioning. Age was negatively associated with cognitive functioning; this association was stronger for older adults in China. Furthermore, sleep problems and edentulism (loss of all natural teeth) were strongly associated with lower cognitive functioning. Being underweight was associated with lower cognitive functioning in India. Poor self-rated health was associated with lower cognitive functioning in India $(\beta=-1.52$, CI: $-2.09,-0.95, p<.001)$ and China $(\beta=-2.03$, CI: $-2.50,-1.56, \mathrm{p}<.001)$. Similarly, the association between $1+$ ADL limitations and cognitive functioning was significant in India $(\beta=-1.02, \mathrm{CI}$ : -1.47 , $.56, \mathrm{p}<.001)$ and China $(\beta=-2.77, \mathrm{CI}:-3.38,-2.17$, $\mathrm{p}<.001)$. Both self-reported diagnosed depression and physical inactivity were significantly associated with cognitive functioning in India.

The association between life course SES and cognitive functioning is presented in Table 3. The combination of parental education and respondent's education with 
Table 1 Characteristics of the study population, WHO-SAGE Wave $1(2007 / 10)$

\begin{tabular}{|c|c|c|c|}
\hline Background Characteristics & Categories & India & China \\
\hline Mean age (years, SD) & & $61.5(8.89)$ & $62.6(8.96)$ \\
\hline Mean height (cm, SD) & & 156.7(9.97) & 159.2(8.68) \\
\hline Mean cognitive functioning (score, SD) & & $38.1(10.01)$ & $50.9(11.8)$ \\
\hline- & & $\%$ & $\%$ \\
\hline \multirow[t]{2}{*}{ Sex } & Male & 51.0 & 49.8 \\
\hline & Female & 49.0 & 50.2 \\
\hline \multirow[t]{2}{*}{ Residence } & Urban & 28.9 & 47.4 \\
\hline & Rural & 71.1 & 52.6 \\
\hline \multirow[t]{2}{*}{ Marital status } & Married & 76.9 & 85.1 \\
\hline & Otherwise & 23.1 & 14.9 \\
\hline \multirow[t]{4}{*}{ Schooling } & No formal education & 50.8 & 22.6 \\
\hline & Less than primary & 10.9 & 18.8 \\
\hline & Completed secondary & 24.4 & 40.9 \\
\hline & Higher secondary (HS) and above & 13.9 & 17.7 \\
\hline \multirow[t]{5}{*}{ Wealth quintile } & Poorest & 18.2 & 16.3 \\
\hline & Poorer & 19.5 & 18.1 \\
\hline & Middle & 18.8 & 20.5 \\
\hline & Richer & 19.6 & 23.3 \\
\hline & Richest & 23.9 & 21.8 \\
\hline \multirow[t]{4}{*}{ Own employment } & Never worked & 27.0 & 8.6 \\
\hline & Informal employment & 22.2 & 2.6 \\
\hline & Self-employed & 36.4 & 45.2 \\
\hline & Private/public sector & 14.4 & 43.6 \\
\hline \multirow[t]{4}{*}{ Mother's education } & No formal education & 90.2 & 87.4 \\
\hline & Less than primary & 5.3 & 6.0 \\
\hline & Completed secondary & 3.9 & 5.1 \\
\hline & Higher secondary (HS) and above & 0.6 & 1.5 \\
\hline \multirow[t]{4}{*}{ Father's education } & No formal education & 66.6 & 68.7 \\
\hline & Less than primary & 13.3 & 12.9 \\
\hline & Completed secondary & 15.4 & 13.9 \\
\hline & Higher secondary (HS) and above & 4.8 & 4.5 \\
\hline \multirow[t]{4}{*}{ Mother's employment } & Never worked & 65.5 & 38.7 \\
\hline & Informal employment & 17.6 & 1.8 \\
\hline & Self-employed & 14.5 & 48.6 \\
\hline & Private/public sector & 2.5 & 10.9 \\
\hline \multirow[t]{4}{*}{ Father's employment } & Never worked & 2.8 & 24.8 \\
\hline & Informal employment & 26.4 & 2.0 \\
\hline & Self-employed & 57.1 & 51.1 \\
\hline & Private/public sector & 13.7 & 22.1 \\
\hline \multirow[t]{4}{*}{ Body mass index } & Underweight & 38.3 & 4.1 \\
\hline & Normal weight & 48.3 & 59.9 \\
\hline & Overweight & 10.6 & 29.9 \\
\hline & Obesity & 2.8 & 6.1 \\
\hline Self-rated health & Good & 77.6 & 78.8 \\
\hline
\end{tabular}


Table 1 Characteristics of the study population, WHO-SAGE Wave 1 (2007/10) (Continued)

\begin{tabular}{|c|c|c|c|}
\hline Background Characteristics & Categories & India & China \\
\hline & Poor & 22.4 & 21.2 \\
\hline \multirow[t]{2}{*}{$1+\mathrm{ADL}$} & No & 47.8 & 87.1 \\
\hline & Yes & 52.2 & 12.9 \\
\hline \multirow[t]{2}{*}{ Sleep problems } & No & 85.5 & 97.3 \\
\hline & Yes & 14.5 & 2.7 \\
\hline \multirow[t]{2}{*}{ Edentulism (Teeth loss) } & No & 84.9 & 90.9 \\
\hline & Yes & 15.1 & 9.1 \\
\hline \multirow[t]{2}{*}{ Tobacco use } & No & 53.1 & 73.6 \\
\hline & Yes & 46.9 & 26.4 \\
\hline \multirow[t]{2}{*}{ Alcohol use } & No & 96.0 & 83.2 \\
\hline & Yes & 4.0 & 16.8 \\
\hline \multirow[t]{2}{*}{ Physical inactivity } & No & 68.5 & 61.2 \\
\hline & Yes & 31.5 & 38.8 \\
\hline \multirow[t]{2}{*}{ Self-reported depression } & No & 95.9 & 99.7 \\
\hline & Yes & 4.1 & 0.3 \\
\hline Observations & - & 6560 & 13,106 \\
\hline
\end{tabular}

cognitive functioning was positive when the mother's education and respondents' education was more than primary schooling in India and China. Similarly, the father's education and respondent's education showed a positive association with cognitive functioning in India and China. The education-based life course SES showed a positive association with cognitive functioning in India and China. Similarly, the employment-based life course SES showed positive association with cognitive functioning in India and China.

Figure 2 shows the predicted cognitive functioning score for India and China by parental education across different ages. We used the interaction between age and parental education to show the change in the cognitive functioning score with age across parental education categories. Across different ages, cognitive functioning score was higher for older adults whose mother and father had high school and above education.

Figure 3 shows that age pattern of cognitive functioning by respondent's educational attainment and wealth quintile. In India and China, older adults who has completed higher secondary (HS) or above had higher cognitive functioning across different ages, more strongly in India. The cognitive functioning score is much lower across age among older adults who had no formal schooling than those who completed higher secondary (HS) or above in China. Wealthier older adults in India had higher cognitive functioning in 50-60 years of age, however, the wealth differences in cognitive functioning narrowed in older ages, suggesting the convergence of cognitive functioning by economic status at older ages.

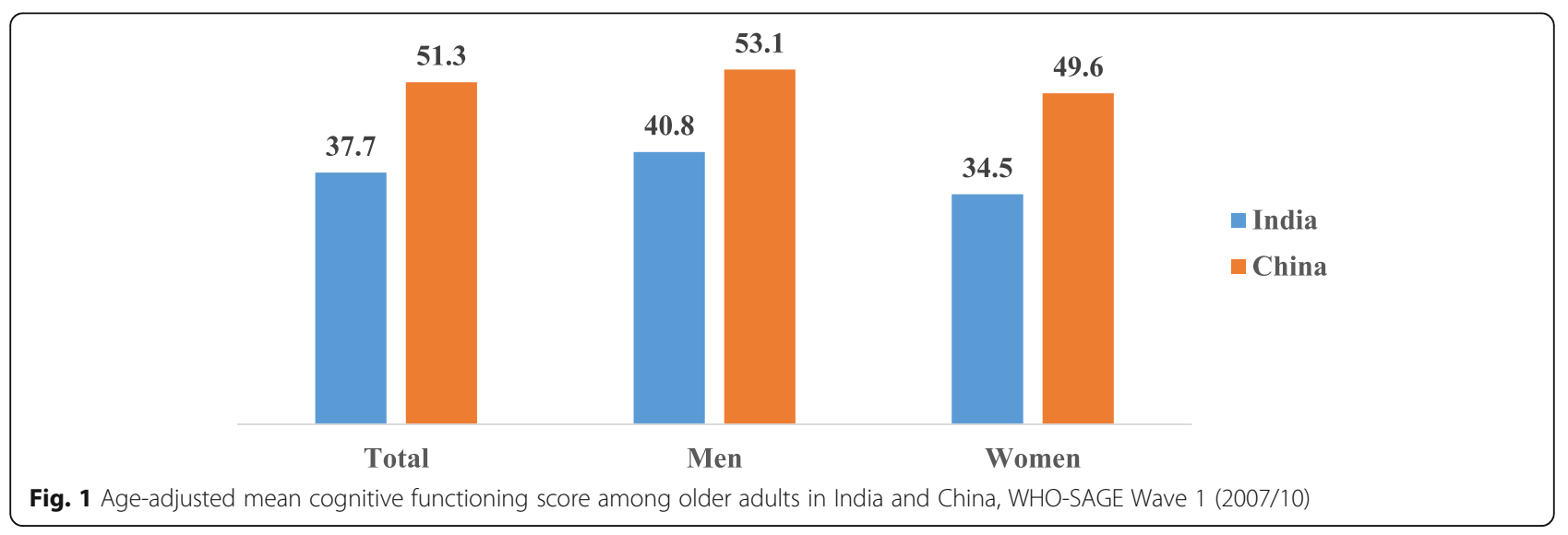


Table 2 Mixed effect linear regression results of cognitive functioning among older adults for India and China, WHO-SAGE Wave 1 (2007/10)

\begin{tabular}{|c|c|c|c|}
\hline Characteristics & Categories & India & China \\
\hline- & - & $\beta(95 \% \mathrm{Cl})$ & $\beta(95 \% \mathrm{Cl})$ \\
\hline \multirow[t]{3}{*}{ Mother's education ${ }^{a}$} & Less than primary & $0.85^{*}(-0.04,1.76)$ & $1.50^{* * *}(0.69,2.31)$ \\
\hline & Completed secondary & $1.53^{* * *}(0.40,2.66)$ & $0.96^{* *}(0.022,1.90)$ \\
\hline & Higher secondary (HS) and above & $3.07^{* *}(0.59,5.56)$ & $2.17^{* * *}(0.54,3.80)$ \\
\hline \multirow[t]{3}{*}{ Father's education ${ }^{a}$} & Less than primary & $0.80^{* *}(0.18,1.43)$ & $1.35^{* * *}(0.76,1.94)$ \\
\hline & Completed secondary & $1.00^{* * *}(0.31,1.68)$ & $1.24^{* * *}(0.60,1.88)$ \\
\hline & Higher secondary (HS) and above & $2.53^{* * *(1.36,3.69)}$ & $3.50^{* * *}(2.43,4.57)$ \\
\hline \multirow[t]{3}{*}{ Mother's employment ${ }^{\mathrm{b}}$} & Informal employment & $0.38(-0.38,1.15)$ & $-0.016(-1.95,1.92)$ \\
\hline & Self-employed & $-0.29(-0.94,0.36)$ & $0.36(-0.42,1.15)$ \\
\hline & Private/public sector & $-0.77(-2.11,0.56)$ & $0.26(-0.50,1.02)$ \\
\hline \multirow[t]{3}{*}{ Father's employment ${ }^{\mathrm{b}}$} & Informal employment & $1.31^{* *}(0.038,2.59)$ & $0.61(-1.15,2.38)$ \\
\hline & Self-employed & $2.15^{* * *}(0.93,3.37)$ & $0.62(-0.17,1.41)$ \\
\hline & Private/public sector & $2.04^{* * *}(0.71,3.37)$ & $0.40(-0.31,1.11)$ \\
\hline \multirow[t]{4}{*}{ Height quintile ${ }^{c}$} & 2 & $0.83^{* *}(0.20,1.46)$ & $0.96^{* * *}(0.39,1.52)$ \\
\hline & 3 & $1.06^{* * *}(0.42,1.70)$ & $1.32^{* * *}(0.76,1.89)$ \\
\hline & 4 & $1.38^{* * *}(0.74,2.02)$ & $1.63^{* * *}(1.03,2.23)$ \\
\hline & Highest & $1.81^{* * *}(1.15,2.47)$ & $2.23^{* * *}(1.60,2.86)$ \\
\hline \multirow[t]{3}{*}{ Schooling $^{a}$} & Less than primary & $3.80^{* * *}(3.11,4.49)$ & $2.96^{* * *}(2.39,3.53)$ \\
\hline & Completed secondary & $5.63^{* * *}(5.03,6.23)$ & $5.44^{* * *}(4.90,5.99)$ \\
\hline & Higher secondary (HS) and above & $9.28^{* * *}(8.45,10.1)$ & $7.82^{* * *}(7.08,8.55)$ \\
\hline \multirow[t]{4}{*}{ Wealth quintile $^{d}$} & Poorer & $0.92^{* * *}(0.24,1.61)$ & $0.75^{* * *}(0.18,1.33)$ \\
\hline & Middle & $1.42^{* * *}(0.71,2.13)$ & $1.02^{* * *}(0.40,1.64)$ \\
\hline & Richer & $2.01^{* * *}(1.28,2.74)$ & $2.28^{* * *}(1.63,2.93)$ \\
\hline & Richest & $2.71 * * *(1.93,3.49)$ & $2.07^{* * *}(1.34,2.81)$ \\
\hline \multirow[t]{3}{*}{ Own employment ${ }^{\mathrm{b}}$} & Informal employment & $0.56(-0.16,1.29)$ & $1.21 *(-0.11,2.54)$ \\
\hline & Self-employed & $0.42(-0.23,1.07)$ & $0.39(-0.42,1.21)$ \\
\hline & Private/public sector & $1.21 * * *(0.44,1.98)$ & $2.47^{* * *}(1.68,3.25)$ \\
\hline Age (years) & & $-0.08^{* * *}(-0.11,-0.06)$ & $-0.26^{* * *}(-0.28,-0.23)$ \\
\hline Gender $^{\mathrm{e}}$ & Female & $-2.96^{* * *}(-3.54,-2.38)$ & $-1.57^{* * *}(-2.02,-1.12)$ \\
\hline Residence $^{f}$ & Rural & $-0.72^{* *}(-1.42,-0.019)$ & $-0.73(-2.14,0.68)$ \\
\hline Marital status ${ }^{9}$ & Otherwise & $-1.09^{* * *}(-1.60,-0.57)$ & $-0.82^{* * *}(-1.33,-0.31)$ \\
\hline \multirow[t]{3}{*}{ Body mass index ${ }^{h}$} & Underweight & $-0.86^{* * *}(-1.31,-0.40)$ & $-0.15(-1.04,0.72)$ \\
\hline & Overweight & $0.89^{* * *}(0.24,1.54)$ & $0.33^{*}(-0.06,0.73)$ \\
\hline & Obesity & $0.66(-0.47,1.80)$ & $-0.12(-0.90,0.66)$ \\
\hline Sleep problems & & $-0.60^{*}(-1.25,0.041)$ & $-1.14^{*}(-2.31,0.018)$ \\
\hline Edentulism & & $-0.63^{* *}(-1.23,-0.038)$ & $-1.27^{* * *}(-1.87,-0.66)$ \\
\hline Poor self-rated health & & $-1.52^{* * *}(-2.09,-0.95)$ & $-2.03^{* * *}(-2.50,-1.56)$ \\
\hline $1+\mathrm{ADL}$ & & $-1.02^{* * *}(-1.47,-0.56)$ & $-2.77^{* * *}(-3.38,-2.17)$ \\
\hline Tobacco use & & $0.08(-0.36,0.52)$ & $0.05(-0.44,0.55)$ \\
\hline Alcohol use & & $-0.99^{*}(-2.03,0.035)$ & $-0.29(-0.83,0.25)$ \\
\hline Physically inactive & & $-1.31^{* * *}(-1.78,-0.84)$ & $0.03(-0.36,0.43)$ \\
\hline Self-reported depression & & $-1.35^{* *}(-2.39,-0.32)$ & $-2.81 *(-6.04,0.42)$ \\
\hline
\end{tabular}

\section{Random part}


Table 2 Mixed effect linear regression results of cognitive functioning among older adults for India and China, WHO-SAGE Wave 1 (2007/10) (Continued)

\begin{tabular}{llll}
\hline Characteristics & Categories & India & China \\
\hline Region & & $0.84(0.41,1.73)$ & $1.49(.74,2.98)$ \\
PSU & & $1.96(1.70,2.26)$ & $2.56(2.09,3.13)$ \\
Individual & - & $7.44(7.30,7.58)$ & $9.25(9.13,9.37)$ \\
Observations & - & 5787 & 10,934
\end{tabular}

${ }^{a}$ reference no formal education, ${ }^{b}$ reference never worked, ${ }^{c}$ reference lowest, ${ }^{d}$ reference poorest, ${ }^{\mathrm{e}}$ reference male, ${ }^{\mathrm{f}}$ reference urban, ${ }^{\mathrm{g}}$ reference currently married, ${ }^{\mathrm{h}}$ reference normal weight

Cl confidence interval ${ }^{* *} p<.001,{ }^{* *} p<.005,{ }^{*} p<.01$

Table 3 Life course SES and cognitive functioning among older adults in India and China, WHO-SAGE Wave 1 (2007/10)

\begin{tabular}{|c|c|c|c|}
\hline Life-course SES & & India & China \\
\hline & & $\beta(95 \% \mathrm{Cl})$ & $\beta(95 \% \mathrm{Cl})$ \\
\hline Mother's education & Own education & & \\
\hline Less than primary & Less than primary & Ref & Ref \\
\hline Greater than primary & Less than primary & $0.74(-1.89,3.38)$ & $0.23(-2.66,3.13)$ \\
\hline Less than primary & Greater than primary & $5.66^{* * *}(5.14,6.19)$ & $4.39 * * *(3.94,4.83)$ \\
\hline Greater than primary & Greater than primary & $8.73^{* * *}(7.60,9.86)$ & $6.91^{* * *}(6.00,7.81)$ \\
\hline Father's education & Own education & - & - \\
\hline Less than primary & Less than primary & Ref & Ref \\
\hline Greater than primary & Less than primary & $0.88^{*}(-0.08,1.84)$ & $1.15^{* *}(.027,2.28)$ \\
\hline Less than primary & Greater than primary & $5.16^{* * *}(4.58,5.74)$ & $4.23^{* * *}(3.77,4.69)$ \\
\hline Greater than primary & Greater than primary & $7.59^{* * *}(6.85,8.33)$ & $6.45^{* * *}(5.76,7.14)$ \\
\hline Mother's employment & Own employment & - & - \\
\hline Not employed & Not employed & Ref & Ref \\
\hline Not employed & Employed & $1.77^{* * *}(0.62,2.93)$ & $1.10(-0.51,2.73)$ \\
\hline Employed & Not employed & $1.14^{* * *}(0.50,1.78)$ & $1.74^{* * *}(0.92,2.56)$ \\
\hline Employed & Employed & $0.70^{* *}(0.028,1.38)$ & $2.16^{* * *}(1.30,3.03)$ \\
\hline Father's employment & Own employment & - & - \\
\hline Not employed & Not employed & Ref & Ref \\
\hline Not employed & Employed & $1.81 *(-0.21,3.84)$ & $1.13 *(-0.18,2.45)$ \\
\hline Employed & Not employed & $0.48(-1.87,2.84)$ & $1.79^{* * *}(0.89,2.68)$ \\
\hline Employed & Employed & $2.39 * *(0.39,4.39)$ & $2.26^{* * *}(1.37,3.15)$ \\
\hline Parental education & Own education & - & - \\
\hline Less than primary & Less than primary & Ref & Ref \\
\hline Greater than primary & Less than primary & $1.74(-1.83,5.32)$ & $3.62(-2.75,10.0)$ \\
\hline Less than primary & Greater than primary & $5.04^{* * *}(4.45,5.63)$ & $5.31^{* * *}(4.54,6.09)$ \\
\hline Greater than primary & Greater than primary & $9.75^{* * *}(8.49,11.0)$ & $8.65^{* * *}(6.25,11.1)$ \\
\hline Parental employment & Own employment & - & - \\
\hline Not employed & Not employed & Ref & Ref \\
\hline Not employed & Employed & $3.99^{* * *}(1.60,6.38)$ & $1.14(-0.58,2.87)$ \\
\hline Employed & Not employed & $0.05(-2.41,2.52)$ & $1.86^{* * *}(0.93,2.80)$ \\
\hline Employed & Employed & $2.67^{* *}(0.48,4.86)$ & $2.46^{* * *}(1.49,3.43)$ \\
\hline
\end{tabular}

Separate regression analysis was performed for each predictor variable adjusting demographic and health variables $\mathrm{Cl}$ confidence interval ${ }^{* * *} \mathrm{p}<.001,{ }^{* *} \mathrm{p}<.005,{ }^{*} \mathrm{p}<.01$ 


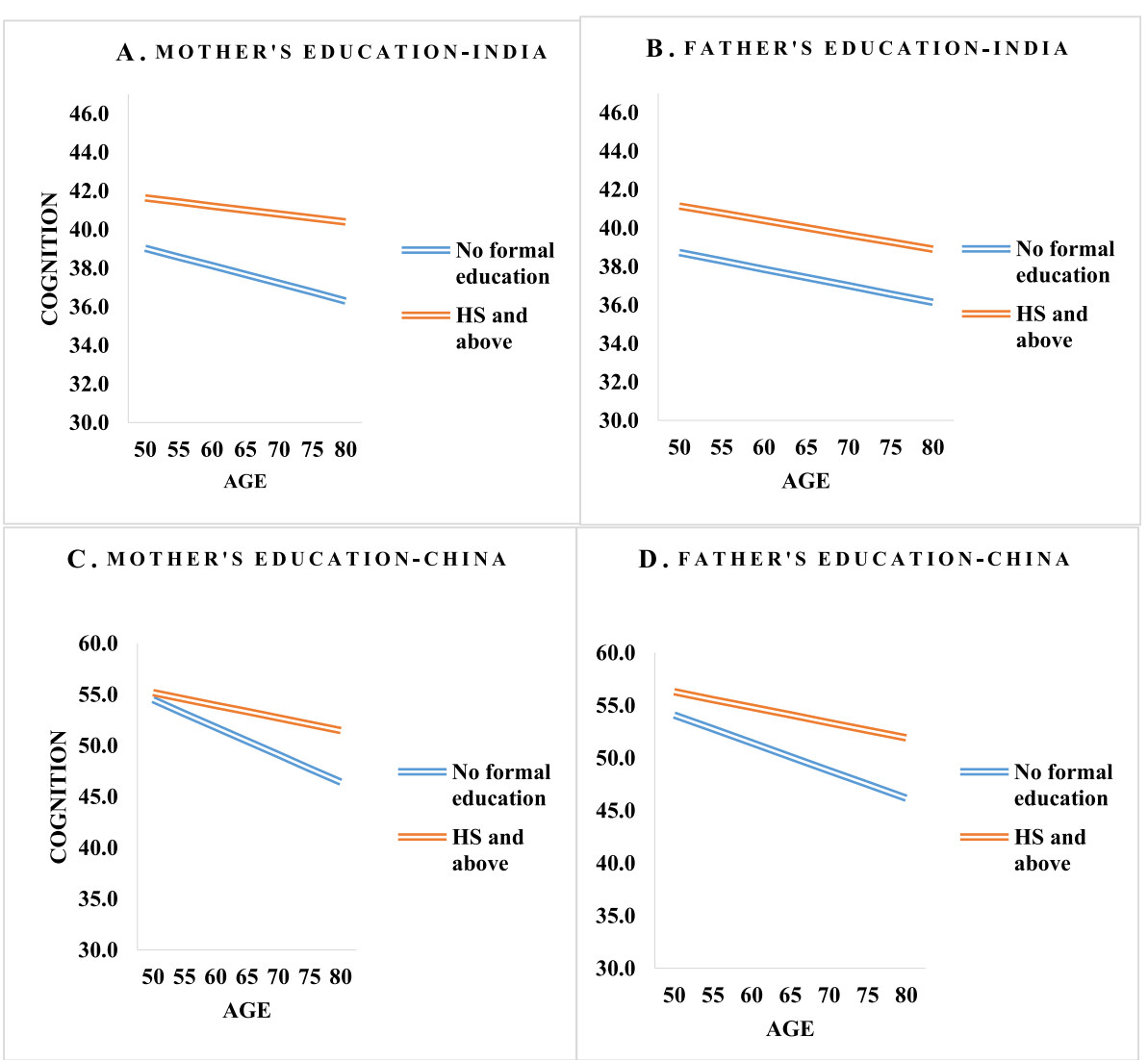

Fig. 2 Predicted cognitive functioning score by parental education categories and age controlling socio-demographic, and health variables for India and China, WHO-SAGE Wave 1. A and B. Age pattern of cognition score of the study participants by mother's and father's education categories in India. C and $\mathbf{D}$. Age pattern of cognition score of the study participants by mother's and father's education categories in China

\section{Discussion}

In this study, we observed a significant and positive association between parental education, as a measure of childhood socioeconomic status and cognitive functioning of older adults in India and China. Furthermore, respondent's socioeconomic status measured by educational attainment and household economic status (wealth quintile) were strongly associated with cognitive functioning. Particularly, the association of educational attainment and wealth quintile was stronger for India. The association between education and employmentbased life course SES and cognition was significant, suggesting stable high socioeconomic status across the life course is important for higher cognitive functioning. The cognitive functioning score was lower across age among older adults whose parents had no schooling, particularly in China. Height showed a significant and positive association with cognitive functioning in India and China. However, the association was stronger for China. Cross-national and gender differences in cognitive functioning were notable. Older adults in India had lower cognitive functioning scores than their Chinese counterparts. Older women in India had lower cognitive functioning scores than men counterparts. Poor selfrated health, sleep problems and edentulism were negatively associated with cognitive functioning.

Overall, the association of childhood socioeconomic status and height with cognitive functioning was significant in India and China, suggesting the similarities in the association of childhood socioeconomic status and height in determining later life cognitive functioning. The results of this study on the association between parental education and later life cognitive functioning are consistent with the findings of previous studies conducted in China and South Africa suggesting the long-term effect of childhood circumstances in developing countries [27, 28, 31, 32]. We also observed lower cognitive functioning score among older adults whose parents had no schooling across different ages which highlighted the role of childhood circumstances; this is consistent with previous literature [50]. Previous studies including a recent study based on SHARE data for European countries found a significant positive relationship between childhood socioeconomic status and cognitive functioning in old age $[24,26,28-30]$. 


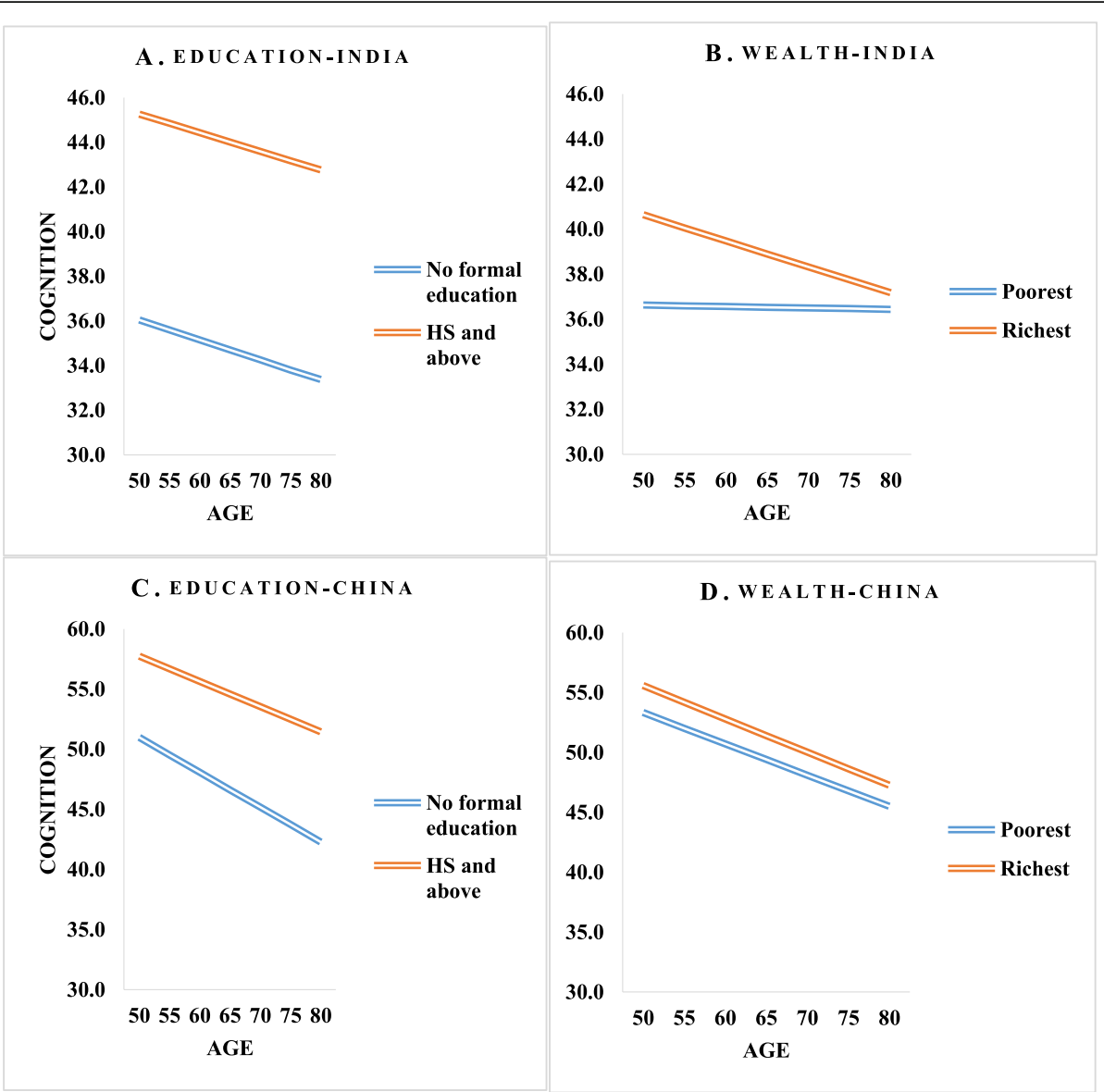

Fig. 3 Predicted cognitive functioning score by education (study participants) and wealth quintile in relation to age controlling demographic, and health variables for India and China, WHO-SAGE Wave 1. A and B. Age pattern of cognition score by participant's education and wealth quintile categories in India. C and $\mathbf{D}$. Age pattern of cognition score by participant's education and wealth quintile categories in China

In this study, educational attainment was found as a strong predictor of cognitive functioning consistent with the findings of previous studies [51-53]. This association is consistent across different ages, suggesting the role of education in cognitive reserve. In China, the cognitive functioning score was higher among older adults with higher secondary (HS) and above education across different age as found in previous literature [50]. These results suggest the role of education in determining cognitive reserve in old age [54]. Low education is associated with a higher risk of cognitive impairment and dementia [55]. In this context, the role of education is seen as a protective factor of cognitive functioning across age. On the other hand, in India, wealthier older adults aged 50-60 had higher cognitive functioning, however, the wealth gradient narrowed after age 60 and above. The results of this study support the convergence of health hypothesis [56] in the Indian context [57]. In the health literature, health inequality tends to narrow in old age mainly as a result of mortality selection [56]. The results of the present study suggest a significant role of economic status as a protective factor of health status and access to nutrition among Indian older adults, specifically in the early age of 50-64.

In this study, height was significantly associated with higher cognitive functioning, as found in previous studies from high and middle-income countries $[28,40]$. The association of height with health-related outcomes suggest a long-lasting relationship of childhood circumstances with later life outcomes. This association is stronger in low and middle-income settings which supports the hypothesis of a stronger effect of childhood circumstances in low-income settings $[58,59]$.

Overall, the findings of better cognitive functioning among older adults in China than India are likely to be result of better educational attainment and nutritional status among older adults in China. Poor self-rated health and $1+$ ADL were negatively associated with cognitive functioning which suggested the significant role of general health and functional limitations on cognitive functioning in old age. Previous studies showed a similar negative association between poor self-rated health and 
cognitive functioning [60]. Poor self-rated health is a well-known indicator of general health which is a strong predictor of mortality [61]. The association between $1+$ ADL and cognition was significant as shown in previous studies [62]. Oral health condition measured as a loss of all natural teeth was negatively associated with cognitive functioning [63].

The results of this study highlighted the significance of childhood socioeconomic status and height in determining late-life cognitive health in low and middle-income settings. Poor socioeconomic status across the life course continues to affect the individual outcomes on various health measures such as handgrip strength [64], frailty [65], and respiratory function [66]. Studies showed that childhood socioeconomic status played an important role in access to nutrition, health, and education which further affect the various individual outcomes throughout the life course $[24,34]$. Especially, parental education has a significant role; educated parents are more likely to escape from the adverse environmental circumstances during pregnancy and better placed in providing better nurturing [67] and immunisation for their children [22, 23]. Childhood health and nutrition mediate as a human capital reserve and have a long-lasting impact on the health and wellbeing of their children. Also, children of educated parent's escape from violence and multiple risk factors through better environmental circumstances with less violence. In contrast, children in poor childhood circumstances experience more health risk behaviour such as smoking and poor dietary habits [68]. Therefore, the role of better childhood circumstances is important in determining health and wellbeing across the life course.

\section{Strengths and limitations}

This study has used measured height data to examine the relationship between height and cognitive functioning, while most of the previous studies used selfreported height $[37,40]$, in this study, we used two important childhood measures; height as a measure of childhood health and net-nutrition and childhood socioeconomic status. Previous studies focussed on either childhood socioeconomic status or height.

The limitations of the study are; the results of this study are based on cross-sectional data. Previous literature showed age-related decline in height $[69,70]$ which is not accounted for in the analysis. Jain and Ma (2020) [70] showed that height shrinkage is associated with lower cognition and health-related outcomes among the elderly. Furthermore, we relied on a few selected measures of childhood socioeconomic status, while several studies have used multiple measures of childhood socioeconomic status. Furthermore, the childhood socioeconomic status was assessed through the retrospective questions in the survey where there is a chance of misreporting. Moreover, in the SAGE survey, the measures of childhood health were not adequately collected unlike other surveys from high-income countries such as Health and Retirement Study (HRS) and Survey of Health, Ageing and Retirement in Europe (SHARE).

\section{Conclusions}

The results of this study suggest that childhood socioeconomic circumstances and adult height as a proxy measure of childhood nutrition play an important role in determining later-life cognition independent of adult socioeconomic status, demographic and health risk factors. In India and China, parental education was significantly associated with cognitive functioning. Educational attainment and household economic status were significant factors in determining cognitive functioning among older adults in India and China. Results highlight the prominent role of parental education and own education across the life course in determining and maintaining better cognitive functioning. The role of wealth quintile in determining cognitive functioning is stronger in middle age to late middle age. Height is an important early life marker in determining cognitive functioning in later life suggesting the strong association of childhood nutrition and health. The findings of this study suggest improving health and nutrition in early childhood tend to have a long-lasting impact on cognitive functioning.

\section{Abbreviations}

SES: Socio-Economic Status; WHO-SAGE: World Health Organisation Study on global AGEing and adult health; HRS: Health and Retirement Study;

SHARE: Survey of Health, Ageing and Retirement in Europe; SRH: Self-Rated Health; ADL: Activities of Daily Living; PSU: Primary Sampling Unit

\section{Supplementary Information}

The online version contains supplementary material available at https://doi. org/10.1186/s12877-021-02303-w.

\section{Additional file 1.}

\section{Acknowledgements}

The authors thank the World Health Organization-Study on global AGEing and adult health (SAGE), for providing data access. SAGE survey was supported by the Division of Behavioral and Social Research, National Institute on Aging and the Department of Health Statistics and Information Systems, World Health Organization (Grant 1 R01 AG034479-01A1). We are also thankful to Dr. Pushpendra Singh and Dr. Aravinda Meera Guntupalli for their help during preparation of the manuscript.

\section{Authors' contributions}

Y.S designed and wrote the initial draft and performed analysis. P. A conceptualized the study and provided critical revisions in content, data analysis and interpretation, and manuscript revision. Y. S and P. A reviewed and approved the final version of the manuscript.

\section{Funding}

The authors received no specific funding for this work.

Availability of data and materials

The data-sets used in the present study are available from the corresponding author on request. 


\section{Declarations}

\section{Ethics approval and consent to participate}

This study has used secondary data, which is in public domain. Therefore, ethical approval and consent to participate are not required.

\section{Consent for publication}

Not applicable.

\section{Competing interests}

The authors declare that they have no competing interest.

\section{Author details}

'International Institute for Population Sciences (IIPS), Govandi Station Road, Mumbai 400088, India. ${ }^{2}$ Department of Development Studies, International Institute for Population Sciences (IIPS), Govandi Station Road, Mumbai 400088, India.

Received: 3 September 2020 Accepted: 26 May 2021

Published online: 09 June 2021

\section{References}

1. Singh GK, Liu J. Health improvements have been more rapid and widespread in China than in India: a comparative analysis of health and socioeconomic trends from 1960 to 2011. Int J MCH AIDS. 2012;1(1):31-48. https://doi.org/10.21106/ijma.11.

2. United Nations. Department of economic and social affairs, population division. world population prospects: The 2015 revision, key findings and advance tables. InTechnical Report: Working Paper No. ESA/P/WP; 2015. p. 241.

3. Ahmed R, Kesavayuth D, Zikos V. Does being smarter make you happier? Evidence from Europe. J Behav Exp Econ. 2018 Oct 1;76:55-67. https://doi. org/10.1016/j.socec.2018.06.004

4. Jokela M, Singh-Manoux A, Ferrie JE, Gimeno D, Akbaraly TN, Shipley MJ, et al. The association of cognitive performance with mental health and physical functioning strengthens with age: the Whitehall II cohort study. Psychol Med. 2010 May;40(5):837-45. https://doi.org/10.1017/S0033291 709991024.

5. Shimada H, Makizako H, Doi T, Tsutsumimoto K, Lee S, Suzuki T. Cognitive impairment and disability in older Japanese adults. PLoS One. 2016 Jul 14 11(7):e0158720. https://doi.org/10.1371/journal.pone.0158720

6. Batty GD, Deary IJ, Zaninotto P. Association of cognitive function with cause-specific mortality in middle and older age: follow-up of participants in the english longitudinal study of ageing. Am J Epidemiol. 2016 Feb 1 183(3):183-90. https://doi.org/10.1093/aje/kwv139.

7. Gottfredson LS, Deary IJ. Intelligence predicts health and longevity, but why? Curr Dir Psychol Sci. 2004 Feb;13(1):1-4. https://doi.org/10.1111/j.09637214.2004.01301001.x.

8. McGuire LC, Ford ES, Ajani UA. The impact of cognitive functioning on mortality and the development of functional disability in older adults with diabetes: the second longitudinal study on aging. BMC Geriatr. 2006 Dec 1; 6(1):8. https://doi.org/10.1186/1471-2318-6-8.

9. Singh P, Govil D, Kumar V, Kumar J. Cognitive impairment and quality of life among elderly in India. Appl Res Qual Life. 2017 Dec 1;12(4):963-79. https:// doi.org/10.1007/s11482-016-9499-y.

10. An J, Li H, Tang Z, Zheng D, Guo J, Liu Y, et al. Cognitive impairment and risk of all-cause and cardiovascular disease mortality over 20-year follow-up: results from the BLSA. J Am Heart Assoc. 2018 Aug 7;7(15):e008252. https:// doi.org/10.1161/JAHA.117.008252.

11. Ramírez-Vélez R, Correa-Bautista JE, García-Hermoso A, Cano CA, Izquierdo $M$. Reference values for handgrip strength and their association with intrinsic capacity domains among older adults. J Cachexia Sarcopenia Muscle. 2019 Apr;10(2):278-86. https://doi.org/10.1002/jcsm.12373.

12. Skirbekk V, Loichinger $E$, Weber $D$. Variation in cognitive functioning as a refined approach to comparing aging across countries. Proc Natl Acad Sci. 2012 Jan 17;109(3):770-4. https://doi.org/10.1073/pnas.1112173109.

13. Wu F, Guo Y, Zheng Y, Ma W, Kowal P, Chatterji S, et al. Social-economic status and cognitive performance among Chinese aged 50 years and older. PLoS One. 2016 Nov 18:11(11):e0166986. https://doi.org/10.1371/journal. pone.0166986
14. Yang L, Martikainen P, Silventoinen $K$, Konttinen $H$. Association of socioeconomic status and cognitive functioning change among elderly Chinese people. Age Ageing. 2016 Sep 1;45(5):674-80. https://doi.org/10.1 093/ageing/afw107.

15. Fors S, Lennartsson C, Lundberg O. Childhood living conditions, socioeconomic position in adulthood, and cognition in later life: exploring the associations. J Gerontol B Psychol Sci Soc Sci. 2009;64(6):750-7.

16. Doblhammer G, Van den Berg GJ, Fritze T. Economic conditions at the time of birth and cognitive abilities late in life: evidence from ten European countries. PLoS One. 2013 Sep 11;8(9):e74915. https://doi.org/10.1371/journa I.pone.0074915.

17. Flynn JR. Massive IQ gains in 14 nations: What IQ tests really measure. Psychol Bull. 1987 Mar;101(2):171-91. https://doi.org/10.1037/0033-2909. 01.2.171.

18. Flynn JR. Requiem for nutrition as the cause of IQ gains: Raven's gains in Britain 1938-2008. Econ Hum Biol. 2009 Mar 1;7(1):18-27. https://doi.org/1 0.1016/j.ehb.2009.01.009.

19. Baker DP, Eslinger PJ, Benavides M, Peters E, Dieckmann NF, Leon J. The cognitive impact of the education revolution: a possible cause of the Flynn effect on population IQ. Intelligence. 2015 Mar 1;49:144-58. https://doi.org/1 0.1016/j.intell.2015.01.003.

20. Vukojevic M, Zovko A, Talic I, Tanovic M, Resic B, Vrdoljak I, et al. Parental socioeconomic status as a predictor of physical and mental health outcomes in children-literature review. Acta Clin Croat. 2017 Dec 1;56(4): 742-8. https://doi.org/10.20471/acc.2017.56.04.23.

21. Currie J, Goodman J. Parental Socioeconomic Status, Child Health, and Human Capital. In: Peterson P, Baker E, McGaw B, editors. International Encyclopedia of Education. Elsevier; 2010. p. 253-9. https://scholar.harvard. edu/files/joshuagoodman/files/parentalses.pdf.

22. Vikram K, Vanneman $\mathrm{R}$, Desai S. Linkages between maternal education and childhood immunization in India. Soc Sci Med. 2012 Jul 1;75(2):331-9. https://doi.org/10.1016/j.socscimed.2012.02.043.

23. Vikram K, Vanneman R. Maternal education and the multidimensionality of child health outcomes in India. J Biosoc Sci. 2020 Jan:52(1):57-77. https:// doi.org/10.1017/S0021932019000245.

24. McEniry M. Early-life conditions and older adult health in low-and middleincome countries: a review. J Dev Orig Health Dis. 2013;4(1):10-29. https:// doi.org/10.1017/S2040174412000499.

25. Aartsen MJ, Cheval B, Sieber S, Van der Linden BW, Gabriel R, Courvoisier DS, et al. Advantaged socioeconomic conditions in childhood are associated with higher cognitive functioning but stronger cognitive decline in older age. Proc Natl Acad Sci. 2019;116(12):5478-86. https://doi.org/10.1 073/pnas.1807679116

26. Kaplan GA, Turrell G, Lynch JW, Everson SA, Helkala EL, Salonen JT. Childhood socioeconomic position and cognitive function in adulthood. Int J Epidemiol. 2001 Apr 1;30(2):256-63. https://doi.org/10.1093/ije/30.2.256.

27. Luo Y, Waite LJ. The impact of childhood and adult SES on physical, mental, and cognitive well-being in later life. J Gerontol Ser B Psychol Sci Soc Sci. 2005 Mar 1:60(2):S93-101. https://doi.org/10.1093/geronb/60.2.593.

28. Kobayashi LC, Glymour MM, Kahn K, Payne CF, Wagner RG, Montana L, et al. Childhood deprivation and later-life cognitive function in a populationbased study of older rural south Africans. Soc Sci Med. 2017 Oct 1;190:20-8. https://doi.org/10.1016/j.socscimed.2017.08.009.

29. Rogers MA, Plassman BL, Kabeto M, Fisher GG, McArdle JJ, Llewellyn DJ, et al. Parental education and late-life dementia in the United States. J Geriatr Psychiatry Neurol. 2009 Mar;22(1):71-80. https://doi.org/10.1177/0891 988708328220.

30. Zhang Z, Liu J, Li L, Xu H. The long arm of childhood in China: early-life conditions and cognitive function among middle-aged and older adults. Journal of aging and health. 2018 Sep;30(8):1319-44. https://doi.org/10.11 77/0898264317715975

31. Yang L, Wang Z. Early-life conditions and cognitive function in middleand old-aged Chinese adults: a longitudinal study. Int J Environ Res Public Health. 2020 Jan;17(10):3451. https://doi.org/10.3390/ijerph171034 51.

32. Sha T, Yan Y, Cheng W. Associations of childhood socioeconomic status with mid-life and late-life cognition in Chinese middle-aged and older population based on a 5-year period cohort study. Int I Geriatr Psychiatry. 2018 Oct;33(10):1335-45. https://doi.org/10.1002/gps.4930.

33. Bozzoli C, Deaton A, Quintana-Domeque C. Adult height and childhood disease. Demography. 2009;46(4):647-69. https://doi.org/10.1353/dem.0.0079. 
34. Deaton A. Height, health, and development. Proc Natl Acad Sci. 2007 Aug 14;104(33):13232-7. https://doi.org/10.1073/pnas.0611500104.

35. Silventoinen K. Determinants of variation in adult body height. J Biosoc Sci. 2003 Apr 1;35(2):263-85. https://doi.org/10.1017/S0021932003002633.

36. Silventoinen K, Lahelma E, Rahkonen O. Social background, adult bodyheight and health. Int J Epidemiol. 1999 Oct 1;28(5):911-8. https://doi.org/1 0.1093/ije/28.5.911.

37. Case A, Paxson C. Stature and status: height, ability, and labor market outcomes. J Polit Econ. 2008 Jun;1 16(3):499-532. https://doi.org/10.1086/ 589524.

38. Vogl TS. Height, skills, and labor market outcomes in Mexico. J Dev Econ. 2014 Mar 1;107:84-96. https://doi.org/10.1016/j.jdeveco.2013.11.007.

39. Maurer J. Height, education and later-life cognition in Latin America and the Caribbean. Econ Hum Biol. 2010 Jul 1;8(2):168-76. https://doi.org/10.101 6/j.ehb.2010.05.013.

40. Guven C, Lee WS. Height, aging and cognitive abilities across Europe. Econ Hum Biol. 2015 Jan 1;16:16-29. https://doi.org/10.1016/j.ehb.2013.12.005.

41. Beeri MS, Davidson M, Silverman JM, Noy S, Schmeidler J, Goldbourt U. Relationship between body height and dementia. Am J Geriatr Psychiatry. 2005 Feb 1;13(2):116-23. https://doi.org/10.1097/00019442-20050200000005.

42. Russ TC, Kivimäki M, Starr JM, Stamatakis E, Batty GD. Height in relation to dementia death: individual participant meta-analysis of 18 UK prospective cohort studies. Br J Psychiatry. 2014 Nov;205(5):348-54. https://doi.org/10.11 92/bjp.bp.113.142984.

43. Jørgensen TS, Okholm GT, Christensen K, Sørensen TI, Osler M. Body height in young adult men and risk of dementia later in adult life. Elife. 2020;9: e51168. https://doi.org/10.7554/eLife.51168.

44. Deaton A, Arora R. Life at the top: the benefits of height. Econ Hum Biol. 2009 Jul 1;7(2):133-6. https://doi.org/10.1016/j.ehb.2009.06.001.

45. McGovern ME. Comparing the relationship between stature and later life health in six low and middle income countries. J Econ Ageing. 2014;4:12848. https://doi.org/10.1016/j.jeoa.2014.09.011.

46. Sohn K. Height and happiness in a developing country. J Happiness Stud. 2016 Feb 1;17(1):1-23. https://doi.org/10.1007/s10902-014-9566-8.

47. Kowal P, Chatterii S, Naidoo N, Biritwum R, Fan W, Lopez Ridaura R, et al. Data resource profile: the World Health Organization study on global AGEing and adult health (SAGE). Int J Epidemiol. 2012;41(6):1639-49. https:// doi.org/10.1093/ije/dys210.

48. Selvamani Y, Singh P. Socioeconomic patterns of underweight and its association with self-rated health, cognition and quality of life among older adults in India. PLoS One. 2018 Mar 7;13(3):e0193979. https://doi.org/10.13 71/journal.pone.0193979.

49. Akinyemiju T, Ogunsina K, Sakhuja S, Ogbhodo V, Braithwaite D. Life-course socioeconomic status and breast and cervical cancer screening: analysis of the WHO's study on global ageing and adult health (SAGE). BMJ Open. 2016 Nov 1;6(11):e012753. https://doi.org/10.1136/bmjopen-2016-012753.

50. Zaninotto $P$, Batty GD, Allerhand $M$, Deary IJ. Cognitive function trajectories and their determinants in older people: 8 years of follow-up in the English longitudinal study of ageing. J Epidemiol Community Health. 2018 Aug 1; 72(8):685-94. https://doi.org/10.1136/jech-2017-210116.

51. Foverskov E, Glymour MM, Mortensen EL, Holm A, Lange T, Lund R. Education and cognitive aging: accounting for selection and confounding in linkage of data from the Danish registry and survey of health, ageing and retirement in Europe. Am J Epidemiol. 2018 Nov 1;187(11):2423-30. https:// doi.org/10.1093/aje/kwy162.

52. Clouston SA, Smith DM, Mukherjee S, Zhang Y, Hou W, Link BG, et al. Education and cognitive decline: An integrative analysis of global longitudinal studies of cognitive aging. J Gerontol. 2020;75(7):e151-60. https://doi.org/10.1093/geronb/gbz053.

53. Yaffe K, Fiocco AJ, Lindquist $K$, Vittinghoff E, Simonsick EM, Newman AB, et al. Predictors of maintaining cognitive function in older adults: the health ABC study. Neurology. 2009;72(23):2029-35. https://doi.org/10.1212/WNL. Ob013e3181a92c36.

54. Farfel JM, Nitrini R, Suemoto CK, Grinberg LT, Ferretti RE, Leite RE, et al. Very low levels of education and cognitive reserve: a clinicopathologic study. Neurology. 2013;81(7):650-7. https://doi.org/10.1212/WNL.0b013e3182a08f1 b.

55. Prince $M, A$ costa $D$, Ferri $C P$, Guerra $M$, Huang $Y$, Rodriguez JJ, et al. Dementia incidence and mortality in middle-income countries, and associations with indicators of cognitive reserve: a 10/66 dementia research group population-based cohort study. Lancet. 2012;380(9836):50-8. https:// doi.org/10.1016/S0140-6736(12)60399-7.

56. Beckett M. Converging health inequalities in later life-an artifact of mortality selection? J Health Soc Behav. 2000;1:106-19.

57. Arokiasamy P, Selvamani Y. Age, socioeconomic patterns and regional variations in grip strength among older adults (50+) in India: evidence from WHO's study on global ageing and adult health (SAGE). Arch Gerontol Geriatr. 2018 May 1;76:100-5. https://doi.org/10.1016/j.archger.2018.02.007.

58. Perkins JM, Subramanian SV, Davey Smith G, Özaltin E. Adult height, nutrition, and population health. Nutr Rev. 2016 Mar 1;74(3):149-65. https:// doi.org/10.1093/nutrit/nuv105.

59. Currie J, Vogl T. Early-life health and adult circumstance in developing countries. Annu Rev Econ. 2013 Aug 2;5(1):1-36. https://doi.org/10.1146/a nnurev-economics-081412-103704.

60. Bond J, Dickinson HO, Matthews F, Jagger C, Brayne C, CFAS M. Self-rated health status as a predictor of death, functional and cognitive impairment: a longitudinal cohort study. Eur J Ageing. 2006;3(4):193-206. https://doi.org/1 0.1007/s10433-006-0039-8

61. Idler EL, Benyamini Y. Self-rated health and mortality: a review of twentyseven community studies. J Health Soc Behav. 1997;1:21-37.

62. Mograbi DC, de Assis FC, Fichman HC, Paradela EM, Lourenço RA. Relationship between activities of daily living and cognitive ability in a sample of older adults with heterogeneous educational level. Ann Indian Acad Neurol. 2014;17(1):71-6. https://doi.org/10.4103/0972-2327.128558.

63. Li J, Xu H, Pan W, Wu B. Association between tooth loss and cognitive decline: a 13-year longitudinal study of Chinese older adults. PLoS One. 2017 Feb 3;12(2):e0171404. https://doi.org/10.1371/journal.pone.0171404.

64. Cheval B, Boisgontier MP, Orsholits D, Sieber S, Guessous I, Gabriel R, et al. Association of early-and adult-life socioeconomic circumstances with muscle strength in older age. Age Ageing. 2018;47(3):398-407. https://doi. org/10.1093/ageing/afy003.

65. Van der Linden BW, Cheval B, Sieber S, Orsholits D, Guessous I, Stringhini S, et al. Life course socioeconomic conditions and frailty at older ages. J Gerontol. 2020;75(6):1348-57. https://doi.org/10.1093/geronb/gbz018.

66. Cheval B, Chabert C, Orsholits D, Sieber S, Guessous I, Blane D, et al. Disadvantaged early-life socioeconomic circumstances are associated with low respiratory function in older age. The Journals of Gerontology: Series A. 2019 Jun 18;74(7):1134-40. https://doi.org/10.1093/gerona/gly177.

67. Case A, Paxson C. Mothers and others: who invests in children's health? J Health Econ. 2001 May 1;20(3):301-28. https://doi.org/10.1016/S0167-62 96(00)00088-6.

68. Umeda M, Oshio T, Fujii M. The impact of the experience of childhood poverty on adult health-risk behaviors in Japan: a mediation analysis. Int J Equity Health. 2015 Dec 1;14(1):145. https://doi.org/10.1186/s12939-015-02 78-4.

69. Fernihough A, McGovern ME. Physical stature decline and the health status of the elderly population in England. Econ Hum Biol. 2015;16:30-44. https:// doi.org/10.1016/j.ehb.2013.12.010.

70. Jain U, Ma M. Height shrinkage, health and mortality among older adults: evidence from Indonesia. Econ Hum Biol. 2020 May 1;37:100863. https://doi. org/10.1016/j.ehb.2020.100863.

\section{Publisher's Note}

Springer Nature remains neutral with regard to jurisdictional claims in published maps and institutional affiliations.

\section{Ready to submit your research? Choose BMC and benefit from:}

- fast, convenient online submission

- thorough peer review by experienced researchers in your field

- rapid publication on acceptance

- support for research data, including large and complex data types

- gold Open Access which fosters wider collaboration and increased citations

- maximum visibility for your research: over $100 \mathrm{M}$ website views per year

At BMC, research is always in progress.

Learn more biomedcentral.com/submissions 